\title{
A REVIEW OF OUR PRESENT KNOWLEDGE OF THE GEOLOGICAL HISTORY OF THE INSECTS. ${ }^{1}$
}

\author{
By F. M. CARPenter.
}

During the past ten years, subsequent to the publication of Handlirsch's general account of fossil insects in Schröder's "Handbuch der Entomologie" in 1920, many important and unexpected specimens have been discovered. So profound an effect have these new fossils had upon insect paleontology that I venture to invite your attention this evening to a review of our present knowledge of the geological history of the insects, and to a discussion of the main problems which await solution.

First, let us consider what important discoveries the past decade has witnessed. ${ }^{2}$ The Carboniferous rocks, unfortunately, have not made a very large or an unusual contribution. The British coal measure insects, comprising sixty species, have been monographed by Bolton in a work which has added a great deal to our knowledge of certain extinct orders. Pruvost has described a splendid series of new fossils collected at the famous Commentry beds in the central plateau of France, and Bolton has published on a smaller assemblage of insects from the same locality and now contained in the British Museum. In this country, Cockerell has written a comprehensive account of the Carboniferous insects of Maryland. But interesting as all these coal measure insects are, they seem to be quite typical of those which have previously been found in this horizon,

${ }^{1}$ Annual address of the retiring president of the Cambridge Entomological Club, Jan. 14, 1930. Contribution from the Entomological Laboratory of the Bussey Institution, Harvard University, No. 330.

${ }^{2}$ Although Handlirsch's account of fossil insects in the "Handbuch" was published in 1920 , it did not include the results of several important works which appeared a few years earlier. For this reason, the latter (as Tillyard's "Mesozoic Insects of Queensland") are mentioned here. 
including such groups as the Paleodictyoptera, the Blattaria, the Megasecoptera, etc. In marked contrast to this, the Permian has unexpectedly furnished us with a remarkable series of specimens, representing groups which have not previously been reported from this horizon. In 1920 Handlirsch listed from the Permian 97 species of insects, aside from cockroaches; now there over 250, also exclusive of cockroaches, and many additional species are contained in unworked collections recently obtained from Permian deposits. For the most part, these new fossils have been secured at three widely separated localities, in Australia, North Russia, and Kansas. The Australian and Kansan specimens have almost exclusively been studied by Tillyard, while the Russian material has been investigated by Martynov. Of course such fossils have thrown much light on the geological ranges and the phylogenetic origin of our existing groups of insects. We now know that many recent orders had a much longer geological history than had been supposed; for the first time the Mecoptera, Neuroptera, Coleoptera, Diptera, Odonata, Homoptera, Psocoptera, and Orthoptera $^{3}$ have been found in the Paleozoic.

The Mesozoic has likewise contributed much to our collections during the past decade. The Triassic, which had previously been nearly a blank as far as insects were concerned, is now represented by about 120 species, described by Tillyard from Queensland. Martynov has published on another remarkable series from the Jurassic of Turkestan, and his studies are by no means complete. Mention should also be made of Tillyard's monograph of the Liassic dragonflies of England, and Ping's study of the Cretaceous insects of China. The latter work is particularly interesting since it has brought to light the only promising insect deposit of the Cretaceous which has yet been found.

The Tertiary, of course, has played a large part in the recent advances of insect paleontology. The Baltic amber insects have received much attention at the hands of several specialists; certain groups, as the Thysanura, Colembola, and Paussidae, have been completely revised. Cockerell has continued his description of the Florissant and Green River

${ }^{3}$ Undescribed. 
insects, as well as those of the Tertiary of England and others contained in the Burmese amber. Very recently Martynov has described the insect fauna of a newly discovered Tertiary bed in Russia, and Pongraz has written several papers on the fossil insects of Hungary, redescribing many obscure insects which Heer first studied seventy years ago. A few Tertiary insects have been collected at new localities in this hemisphere,--in Tennessee, Washington, Nevada, and Argentina, all of which give much promise of providing us with a more complete series of fossils in the future.

If we take the conventional bird's-eye view of the geological history of the insects, we are at once struck by the antiquity, not only of their natural groups, such as the orders, families, and genera, but of their habits and ethology. As far back as the Oligocene, about 50 million years ago, the social Hymenoptera had already differentiated into several castes, and the ants, at least, had accomplished this by the Middle Eocene. The Baltic amber ants, as demonstrated by Wheeler, show definite polymorphism and even the higher stages of development such as ergatoid and pseudogynic females, and ergatomorphic males. Some of these Oligocene ants had also "learned to attend" plant-lice, just as many of the modern species do. Whether or not some of the amber insects belong to species which are still existing on earth, is an open question. In the case of the ants, there are eight species which are morphologically identical with certain living ones. If these species actually are identical -and there is no evidence to the contrary-then they have existed without apparent structural change for some 50 million years ${ }^{4}$. Aside from the probability of the specific identity of some of our fossil and recent insects, it is certain that most of the genera of the Tertiary are still surviving. Of course many of the genera which used to be more or less cosmopolitan, these many millions of years ago, are now restricted to much smaller areas,-as the dipterous genus, Glossina or the formicid, Oecophylla. As we become more and more acquainted with the tropical insect

\footnotetext{
${ }^{4}$ I have used the time estimates advanced by Dr. A. Holmes, in his "Age of the Earth" (London, 1927).
} 
faunas, we even find genera which were first known to us only as fossils and supposed to have been extinct. Such a genus is Archipsocus, described by Hagen for an amber Psocid, but subsequently found to be existing in the tropics of both the New and the Old World. Another instance is the ant Gesomyrmex, which was originally described by Mayr from the amber, and which was found many years later in the region of Borneo.

Now if we go back another hundred million years on the geological calendar, to the Middle Mesozoic, we are unable to recognize definitely any existing genera, but we do find many families quite familiar to us at the present time. Of course, as one would naturally expect, there is a marked difference in the development of the several orders. All the Mesozoic Trichoptera, for example, belong to extinct families, but many of the Orthoptera and Diptera can be included within modern families. When we reach the Permian, another 50 million years away, we observe that our recent families no longer make their appearance, but we are still able to recognize several existing orders, as the Mecoptera, Neuroptera, Odonata, Diptera, etc., including types with complete metamorphosis. However, receding another 50 million years-making a total of about 250 million-we come to the Upper Carboniferous, in which our earliest winged insects have been found. Here we find an assemblage quite unlike that of any other period, including such primitive forms as the Paleodictyoptera, and a few more highly specialized groups as the Protodonata and Megasecoptera. Only one recent order, Blattaria, has been recognized without question in the Upper Carboniferous ${ }^{5}$. Tillyard has described from even older rocks, the Devonian of Scotland, the remains of some arthropods which he considers to be true Collembola, but I do not believe that entomologists in general have accepted his conclusions. The absence of winged insects from strata below the Upper Carboniferous is particularly disconcerting, for, primitive as these coal measure insects may be, they are nevertheless

${ }^{5}$ Tillyard maintains that the obscure Metropator pusilus Handl., from the Pottsville series of the Upper Carboniferous, is a true Mecopteran, but this is very dubious. See G. C. Crampton's discussion, Psyche, 37, 1930; p. 93. 
perfectly respectable insects and so far along the line of the Insecta that they show no definite relationship with other Arthropods.

With this general survey of insect paleontology in mind, I suggest that we now examine more carefully the geological ranges of the larger and more prominent insect orders. Of the extinct ones certainly the most interesting, phylogenetically, is the Paleodictyoptera. These generalized creatures, which are usually regarded as the ancestors of all the other winged groups, were developed into many diversified families before the end of the Carboniferous; but for some reason their glory was brought to an abrupt end, for only one species is known to have persisted into the Permian. Another interesting Carboniferous order was the Megasecoptera, the members of which were unique among the other known species of the period in that they possessed petiolate wings, not very much unlike those of the damselflies. These insects appear to have completely died out before the Permian, but some recent groups are supposed to be their direct descendants, - as the Odonata and Mecoptera. The order Protodonata, another assemblage which has never been found living, is especially famous because of the large size attained by some of its members, Meganeura of the Commentry of France having a wing-expanse of about 29 inches. This order, in contrast to the foregoing, persisted through the Permian, but apparently became extinct during the Triassic. All the rest of the Carboniferous insects, excluding a few very small orders with obscure affinities, seem to fall into what we may call the Blattoid, or cockroach, complex. Handlirsch and others have attempted to divide them into separate orders, such as the Protorthoptera and Protoblattaria, but these groups overlap in many respects. This complex, in my opinion, represents the converging branches which later lead to several distinct orders of insects; it represents, in other words, the trunk of the conventional phylogenetic tree, where the several branches had joined-or were in the act of joining-into one. I suspect that as more and more Upper Carboniferous insects are found this complex will become even more jumbled; and I also believe that when Lower Carboniferous insects are discovered, as they eventually must, we shall find the Paleo- 


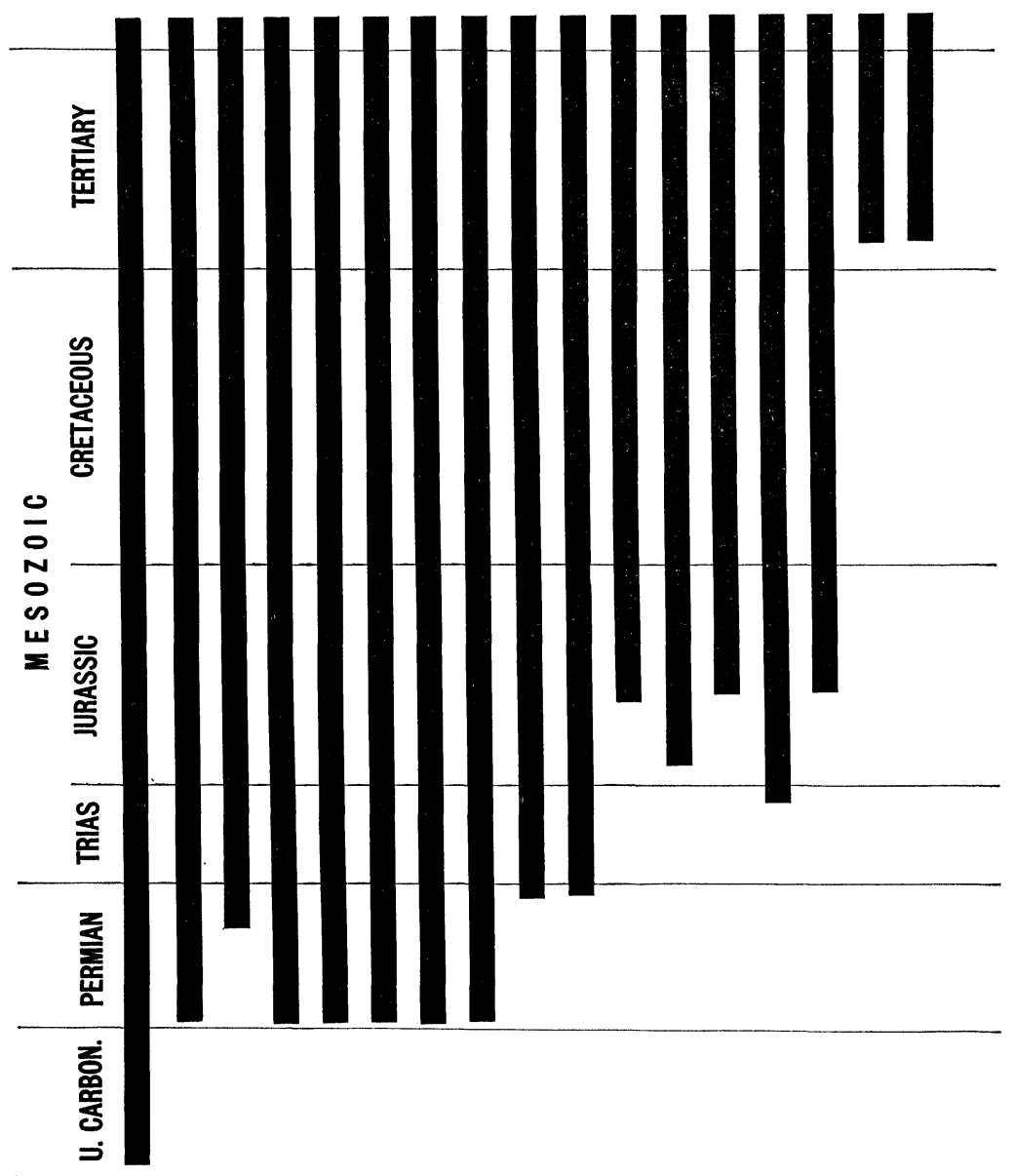

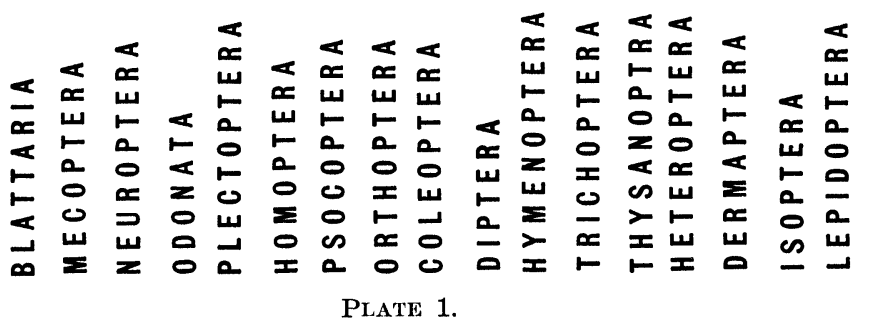

Table 1. Geological Ranges of the Larger Insect Orders. 
dictyoptera, Megasecoptera, and the other extinct orders of the Upper Carboniferous, joining with this complex.

If we examine a diagram showing the geological ranges of the larger existing orders of insects, we are at once impressed by the fact that ten of them have been found in the Permian; of these, seven have been recognized in the Lower Permian, and one, the Blattids, in the Upper Carboniferous. These ten Permian orders are a rather diversified lot, including the Mecoptera, Neuroptera, Odonata, Homoptera, Psocoptera, Coleoptera, Diptera, Plectoptera, Blattaria, and Orthoptera. Since their occurrence in the Permian marks the earliest record of all these insects, except the cockroaches, let us see if these ancient representatives are as primitive as we might expect.

The presence of Mecoptera in the Lower Permian is particularly striking, inasmuch as our recent members of this order develop with complete metamorphosis. Of course since no larval or pupal forms of the Permian Mecoptera have been found, we have no direct evidence that they, too, were holometabolous; but, as Tillyard has pointed out, they are so close to our existing types in other respects that no one would deny that they also possessed holometabolism. There are many features of these ancient scorpion-flies that are most unusual. Those from the Lower Permian of Kansas, with which we are best acquainted, are very minute, having an expanse of about $10 \mathrm{~mm}$.,-less than that of any existing species. Some of the Permian forms had short beaks, like those of the Australian Choristidae; the antennae were shortened and possessed fewer segments than those of any known Mecopteran except the highly specialized Bittacidae; the males of some genera had a genital structure essentially like that of the Bittacidae, also. Finally, some of the Lower Permian species had a wing venation more highly specialized than that of any recent types. The Neuroptera have not yet been taken in the Lower Permian, but those of the Upper Permian were actually more specialized in their venation than their existing relatives. Both the Planipennia and Megaloptera were already differentiated and as highly developed along their own lines as the Mecoptera were along theirs. Although Tillyard maintains that the absence of Neuroptera in the Lower Permian collections is sufficient to show that the 
order was a later development than the Mecoptera, I believe that the Upper Permian specimens demonstrate that the Neuroptera are at least as old a group as the Mecoptera. The finding of true Odonata in the Lower Permian was one of the surprising discoveries of the decade; previously no Odonata had been known from the Paleozoic, but subsequent to the finding of the Lower Permian fossils, an Upper Permian species has also been located. All these described Permian forms possessed petiolate wings, more narrow and elongate than any recent types. As in the case of the Mecoptera, the Permian Odonata were very small, some having a wing-expanse of about $4.0 \mathrm{~cm}$. The absence of Odonata with broad wings basally from the Permian has lead Tillyard to the conclusion that the Anisoptera and the Anisozygoptera were derived from the petiolate Zygoptera during the Triassic. For my own part, I do not accept this inference, but consider that both the anisopterous and zygopterous lines were already developed during the close of the Upper Carboniferous. The occurrence of true Homoptera in the Lower Permian is of much significance, especially since we are forced to admit that they appear to be the most highly specialized of all the insects of this horizon. Numerous Homoptera, even more highly developed, have been taken in the Upper Permian of Australia and Russia. The finding of Psocids in the Lower Permian was perhaps the most surprising discovery made in the field of fossil insects for many years. At the time when these fossils were collected, the earliest record of the order was in the Baltic amber, of Tertiary age, some 200 million years later, but subsequent to the finding of the Permian specimens, Martynov has taken others in the Jurassic of Turkestan. The Permian Psocids were very similar in venation to the Homoptera, and were nearly as highly specialized. The Plectoptera or Ephemerida have long been recognized as very primitive insects, so their presence in Lower Permian beds is not at all surprising. The Permian species, although more primitive than any recent forms, were nevertheless well developed along certain lines and show that the order originated far in the past. The other Permian orders, the Diptera, Orthoptera, and Coleoptera, are too sparsely represented in our collections just now to enable us to form any definite idea as to how far they had developed along their 
particular lines of evolution. But I believe that it is already evident from our discussion of the preceding groups that the Permian orders were far more highly specialized than they should be in the strata where they first make their appearance. Some of them, in fact, such as the Mecoptera, Neuroptera, Odonata, Homoptera, and Psocoptera, were so highly developed that they must have extended as distinct orders well back into the Carboniferous. Now if this is the case, one might wonder why these insects have not been found in the Upper Carboniferous. The explanation, I believe, lies in the coarse nature of the Carboniferous strata in which the insects are preserved. The Lower Permian representatives of the Mecoptera, Odonata, Homoptera, and Psocoptera are very small, those of the first two orders being much smaller than the average existing species of these groups; and all the Neuroptera of the Russian Permian and most of those of the Australian Permian (which is almost Triassic) are also small, their averaging wing-expanse being about two centimeters. The majority of the Carboniferous insect beds are composed of coarse material, and even the finest of them would hardly be capable of preserving such minute insects as those which we have just considered from the Permian. The average wing-expanse of the Carboniferous insects was approximately $10 \mathrm{~cm}$., not including the cockroaches. The wings of the latter were much smaller, but they also possessed the coriaceous texture of the recent species, and were consequently able to be preserved regardless of their smaller dimensions. This selective nature of the Carboniferous strata has given rise to the notion that all the Carboniferous insects were "giants"; but I do not believe this to be the fact, and predict that when some enterprising geologist discovers for us a Carboniferous insect bed with as perfect a preservation as the Wellington shales of Kansas, we shall find some very small insects belonging to the several recent orders which are so highly developed in the Permian.

Let us now consider the orders of insects which make their first appearance in the Mesozoic. There are five of these: the Trichoptera, Heteroptera, Dermaptera, Hymenoptera, and Thysanoptera. Only one, the Heteroptera, has been found in the Triassic; the others are not known earlier than the Jurassic. These oldest Heteroptera were so well 
developed along the lines of the recent species that it seems almost certain that the order must have existed in the Permian. The Trichoptera of the Jurassic, on the other hand, are essentially more primitive than the extant species, many of them possessing a venation so similar to that of their contemporary Mecoptera that it is frequently difficult to distinguish the members of these two orders. Consequently, it is very doubtful if the caddis-flies will ever be found lower than the Triassic. The Hymenoptera are first represented in the Jurassic, by such forms as Siricoids, Oryssoids, and Ichneumonoids. This diversity of the Jurassic Hymenoptera makes it rather obvious that the order had been some time in existence before that period, probably at least as far back at the lower Triassic. The only known Mesozoic Dermaptera and Thysanoptera have been taken in the Turkestan beds, but they are both represented by characteristic types, not very much unlike certain recent species.

We are now left with the two orders whose first record is in the Tertiary rocks,- - the Lepidoptera and Isoptera. Only very few Lepidoptera have been found as fossils in this horizon, but these are absolutely modern in every respect, and there can be no doubt that the group arose some time in the Mesozoic. The Isoptera are quite common in the Tertiary beds and are differentiated into many recent families, most of which, however, are now limited to much smaller geographical areas. There is every indication that the termites will some day turn up in Jurassic and perhaps even Triassic strata.

From the foregoing discussion of the geological ranges of the larger insect orders, it is obvious that by far most of the orders have had a longer history than one would assume from the mere geological occurrence of the oldest species. In every case where we have enough fossils to utilize, we see that the earliest representatives of each order are relatively highly specialized along the lines of the recent types; and this is particularly true of the Permian record. In order to have our diagram represent the probable true range of these orders, we must make several changes: The Mecoptera, Neuroptera, Odonata, Homoptera, Psocoptera, Plectoptera, and of course the Blattids, would extend back to the Upper Carboniferous; the Hemiptera would recede to the Permian, and the Trichoptera, Dermaptera, and 
Thysanoptera to the Triassic, while the Lepidoptera and Isoptera would be shown as far back as the Jurassic only. Whether these estimations are substantiated or not will of course depend entirely upon the future discoveries in insect paleontology.

There is one other aspect of insect paleontology which I wish to discuss: the relative development of each order in the several geological periods. Those of you who have never considered this aspect of entomology will probably be more or less surprised at some of the facts. The average entomologist, if there be such a freak, is so accustomed to thinking of the insect orders in their present relative standings that he never stops to reflect that there must have been some period in the earth's history when the more predominant of the recent orders were actually struggling for a footing; when some of our smaller groups, now nearly extinct, were the predominant ones. Or perhaps the entomologist is, let us say, a hymenopterist, and so fond of his pets that he cannot imagine any period in the earth's history when they were not disconcertingly abundant. But a moment's reflection on the geological history of the other groups of animals will show that such a change in the relative status of the orders is only to be expected. Taking the fishes for an example, we note that the Lung Fishes, which are now represented by a very few species, were one of the most predominant groups during the Devonian and Carboniferous; in a similar manner the Lobe Fishes and the sharks were very abundant during the latter half of the Paleozoic, although both of these types are now greatly outnumbered by more recently evolved forms. Innumerable examples may also be found in the higher vertebrate classes. Among the Reptilia, the Order Crocodilia was represented in the middle Mesozoic by a great number of species, which are now reduced to a small fraction. An even more striking illustration is furnished by the Rhyncocephalia, which were well developed in the number of species during the Triassic, but are now known from a single living species, Sphenodon punctata, of New Zealand. It is only logical, therefore, that we should find that our insect orders have passed thru similar modifications. 
I take it that no one will deny that the number of species in an order is an index to the "health" of that group. At least it is obvious that such an aggregation as the Coleoptera, with close to 200,000 existing species, is in less danger of becoming extinct within the next thousand years than, say, the Mecoptera, of which less than 200 species have been found in all regions of the earth. Consequently, an accurate idea of the "species strength" of the orders can be obtained by determining the percentage of species which each order contributes to the entire insect fauna. The present percentages for some of the existing orders are shown in the right-hand column of figure 2. Here we see that the Mecoptera, Neuroptera, Odonata, Psocoptera, Plectoptera, and Blattaria each make up less than $1 \%$ of the known species. The Orthoptera and Homoptera are but little better, with about $3 \%$ and $3.5 \%$ respectively. The Coleoptera lead with the striking figure of $41 \%$.

TABLE NO. 2.

RELATIVE ABUNDANCE OF SPECIES IN EACH ORDER AT DIFFERENT PERIODS

(Figures in Percentages)

\begin{tabular}{|c|c|c|c|c|}
\hline & Permian & Mesozoic & Tertiary & Recent \\
\hline Mecoptera & 9.0 & 3.7 & .16 & .035 \\
\hline Neuroptera $\ldots \ldots \ldots \ldots \ldots$ & 3.0 & 4.8 & .50 & 42 \\
\hline Odonata $\ldots \ldots \ldots \ldots \ldots$. & .80 & 6.6 & 1.6 & .56 \\
\hline Homoptera...$\ldots \ldots \ldots$ & 12.5 & 9.0 & 4.0 & 3.4 \\
\hline Psocoptera ............. & 6.0 & .25 & .45 & .12 \\
\hline Coleoptera $\ldots \ldots \ldots \ldots \ldots$ & 1.0 & 37.0 & 37.0 & 41.5 \\
\hline Plectoptera $\ldots \ldots \ldots \ldots \ldots$ & 3.5 & 2.0 & .30 & .095 \\
\hline Diptera .. ........... & .30 & 5.0 & 27.0 & 10.8 \\
\hline Orthoptera & .30 & 9.0 & 1.2 & 2.9 \\
\hline Blattaria. & 34.0 & 7.0 & .90 & .42 \\
\hline
\end{tabular}

Even a casual examination of the geological history of the insects will indicate that quite different conditions have prevailed. In the case of the Mecoptera, for instance: 10 species of these insects have been secured in the Lower Permian of Kansas, 4 species in the Russian Permian, and 15 in the Australian Permian, making a total of 29 species from these three deposits. Yet in the Tertiary, which has produced more than twenty times as many species of fossil insects as the Permian, we have found only a total of 12 
Mecoptera in all deposits! When we put this on a percentage basis, the results are even more striking (table 2). We find that the Mecoptera make up about $9 \%$ of the Permian insect fauna, less than $4 \%$ of the Mesozoic, and not even .2\% of the Tertiary; and as I have mentioned above, the Mecoptera contribute less than $.04 \%$ to the recent species. The Neuroptera comprise about $3 \%$ of the Permian insects, nearly $5 \%$ of the Mesozoic, but less than $1 \%$ of the Tertiary and Recent. The Odonata are only represented in the Permian by less than $1 \%$; but in the Mesozoic we find that almost $7 \%$ of the species belong here, while in the Tertiary the figures drop below $2 \%$, and at the present time the Odonata make up about one-half of one per cent. The Homoptera, as I have stated above, are very common in the Permian beds, making up a total of about 12.5; in the Mesozoic this changes to $9 \%$, in the Tertiary and Recent to a little less than $4 \%$. The Psocoptera are also common in the Permian, making up $6 \%$ of the fauna; but less than $.3 \%$ of the Mesozoic, .4\% of the Tertiary and about.1\% of the Recent. The Coleoptera are rare in the Permian, only about $1 \%$ of the species of this horizon belonging here; but in the Mesozoic, Tertiary and Recent about $40 \%$ of the species fall within this order. The Plectoptera make about $4 \%$ of the Permian insects, but this figure drops off gradually from the Mesozoic reaching about .1\% at present. Approximately $.3 \%$ of the Permian insects are Diptera, and this increases to $5 \%$ in the Mesozoic and $27 \%$ in the Tertiary, only to drop again in recent times to about $10 \%$. The Orthoptera are as scarce in the Permian as the Diptera but increase to $9 \%$ in the Mesozoic, then fall off to about $2 \%$. The Blattaria furnish us with an astonishing decline: in the Upper Carboniferous they composed about $57 \%$ of the entire insect world, as we know it; in the Permian, this figure became $34 \%$; in the Mesozoic, $7 \%$; and in the Tertiary and Recent, less than $1 \%$.

I have presented these figures without any implications as to their significance, or without trying to interpret them. It is an undisputable fact that the Mecoptera include $9 \%$ of the known species of Permian insects, $4 \%$ of the Mesozoic, and .2\% of the Tertiary. We now have to determine whether this variation is due merely to chance or to actual 
variation in the specific standing of the groups during the several geological periods. Have the Mecoptera, for example, really been on the wane since the Lower Permian, or are the figures which indicate this without significance? To answer this question one might consider the correlation between the occurrence of the orders in the deposits of each horizon; if the percentages of each order even approximately agreed, we should have positive evidence of the value of our percentages. But this would be a long and tedious recital, so we must find another way of accomplishing similar results. Fortunately Handlirsch in 1908 included in his volume on fossil insects a list of the percentages of the orders, similar to the one which we have considered above. At that time there were 7651 species of fossil insects described. In 1920 Handlirsch again listed the percentages in a similar way for the fossils known at that time, a total of 9302 species. Now there are approximately 10,400 species of fossil insects recognized. That is to say, between the years 1908 and 1920, 1651 species of insects were described; and between 1920 and 1930, a total of 1100 more. These additional species represent the fossils that have been taken in new deposits, as well as those contained in new collections from previously known beds. A comparison, therefore, between the percentages obtained in 1908,1910 , and 1930, furnishes us with a means of determining how closely fossils in new localities, new deposits, and additional collections agree with older records, and consequently a means of determining whether or not our figures have any significance. In table 3 these percentages are listed in parallel columns. We observe at once, of course, the blankness of the Permian record before the 1930 column. This, as I have explained above, is due to the fact that practically no Permian collections had been worked before 1920. We have since found three widely separated Permian beds, each with a diversified fauna, and each sufficiently fossiliferous so that our total of Permian specimens is well over 7000 . We cannot therefore check these Permian figures with earlier ones, to any extent. In 1908 Handlirsch placed the Permian blattids at about $80 \%$. This was because Sellards had described only the cockroaches of the Kansan Permian at that time; in the 1920 column this 
percentage dropped to $57 \%$, for Sellards had by then described the Plectoptera, and a few other groups. Now that all the Permian orders have been studied, we find the figure at $34 \%$, which is probably very close to the correct magnitude. Although we have no previous records to check with those of the 1930 columns, it is interesting that the insect faunas of the several Permian beds compare very closely, although neither the Kansan nor Australian Permian beds have been entirely worked out. We are therefore obliged to regard the Permian record as more or less temporary and probably subject to slight changes when additional material has been found. Just how great these changes are we cannot say at present.

TABLE 3 .

RELATIVE ABUNDANCE OF SPECIES IN EACH ORDER AT DIFFERENT PERIODS, AS DETERMINED IN 1908, 1920, 1930

(Figures in Percentages)

\begin{tabular}{|c|c|c|c|c|c|c|c|c|c|}
\hline & \multicolumn{3}{|c|}{-Permian- } & \multicolumn{3}{|c|}{-Mesozoic- } & \multicolumn{3}{|c|}{-Tertiary- } \\
\hline & 1908 & 1920 & 1930 & 1908 & 1920 & 1930 & 1908 & 1920 & 1930 \\
\hline Mecoptera & & & 9.0 & 2.0 & 3.3 & 3.7 & .11 & .13 & .16 \\
\hline Neuroptera .... & & & 3.0 & 4.0 & 4.1 & 4.8 & .60 & .62 & .50 \\
\hline Odonata..... & & & .80 & 6.8 & 6.2 & 6.6 & 1.5 & 1.3 & 1.6 \\
\hline Homoptera .... & & & 12.5 & 4.0 & 8.0 & 9.0 & 4.0 & 3.6 & 4.0 \\
\hline Pscoptera & & & 6.0 & .15 & .15 & .25 & .40 & .40 & .45 \\
\hline Coleoptera .... & & & 1.0 & 35.0 & 30.0 & 37.0 & 40.0 & 37.0 & 37.0 \\
\hline Plectoptera ... & 2.8 & 7.5 & 3.5 & 1.8 & 1.8 & 2.0 & .30 & .20 & .30 \\
\hline Diptera & & & .30 & 3.5 & 5.0 & 5.0 & 26.0 & 25.0 & 27.0 \\
\hline Orthoptera .... & & 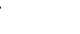 & .30 & 8.0 & 10.0 & 9.0 & 1.2 & 1.2 & 1.2 \\
\hline Blattaria & 80.0 & 57.0 & 34.0 & 8.0 & 7.0 & 7.0 & .70 & 1.0 & .90 \\
\hline
\end{tabular}

Leaving the Paleozoic and passing to the later formations, we note that at the present reckoning the Mecoptera make up about $3.7 \%$ of the Mesozoic insects. Although this is nearly twice the percentage obtained from the 1908 records, it is still vastly lower than the $9 \%$ of the Permian, and equally greater than the Tertiary percentage, which is quite constant in all of the columns. It seems very probable therefore that while the relative number of species of fossil Mecoptera may vary somewhat as additional beds are discovered, these variations will not be sufficient to upset the present trend in the figures, and we are quite safe- 
as safe as any paleontologists-in concluding that the Mecoptera had reached their maximum during the Permian. The Neuroptera show a much more consistent series of figures during the Mesozoic and Tertiary, and it is doubtful in my mind that these percentages will change radically in the future. In this case, however, we see that the Neuroptera appear to make up a higher percentage of the Mesozoic fauna than the Permian one; but the difference is very slight, only a little over $1 \%$, and since the Permian Neuroptera are quite as highly specialized as the Mecoptera of that period, it is very probable that a much larger number of Neuroptera will turn up in new beds. The Odonata in both Mesozoic and Tertiary have been regular in their occurrence, so that there has been hardly any variation in their percentages during the past twenty years. Here the maximum seems to be in the Mesozoic, and the difference between the Permian on the one hand, and the Tertiary on the other is so great (even more so than in the Mecoptera) that it is extremely doubtful that this trend will ever be disturbed. The next order, the Psocoptera, has apparently had a history similar to that of the Mecoptera. While the percentages of these insects in the Mesozoic and Tertiary have varied somewhat, due to the early neglect of these small insects, they are so abundant in the Permian that there are no grounds for supposing that they will ever turn up in the Mesozoic and Tertiary to a similar extent. The Homoptera are the same. It should be noted that there was a great increase in the percentage of the Mesozoic Homoptera between 1908 and 1920, again, as in the case of the Psocids, because these minute insects were not observed in the deposits until after the publication of Handlirsch's "Fossilen Insekten". At the present time, although the percentage of Mesozoic Homoptera is about $9 \%$ of the whole insect fauna of the period, it is very doubtful if this will ever increase to overtake the Permian ratio, where it is $12.5 \%$. When we come to the Coleoptera, we see that the percentage of these in the Mesozoic and Tertiary has been quite stable in collections obtained during the past 20 years. The striking fact, of course, is the evenness of their relative abundance as fossil from the Mesozoic to the present, especially in contrast to the small percentage known in the 
Permian. It is obvious, I think, that the jump from $1 \%$ in the Permian to $37 \%$ in the Mesozoic, is so great as to arouse one's suspicions as to the accuracy of the geological records of these insects. For my own part, I suspect that the fault lies with the Permian, not with the Mesozoic, and that a relatively larger number will be found in the Permian than we know at present; but it seems unlikely that the Permian ratio will ever approach that of the Mesozoic. The Diptera have likewise been constant in their occurrence in insect beds. It certainly does not seem logical that the Tertiary proportions, somewhere around $25 \%$ will ever be exceeded by those of the Mesozoic, which have not gone over $5 \%$. Whether the Diptera were actually twice as abundant relatively in the Tertiary as they are at present, as our figures would indicate, is perhaps open to more question; there is certainly no reason why this order should not have attained its maximum during the Tertiary. When we pass to the Plectoptera or Ephemerids, we again find in the Mesozoic and Tertiary a stable list of percentages. The Tertiary figures are much lower than those of the Mesozoic, and would, in fact, require an increase of $600 \%$ to bring them to the same magnitude. The Permian percentage in the 1930 column are not quite twice those of the Mesozoic, so that it is perfectly possible that sometime we may have sufficient records to show that the may-flies were relatively more abundant in the Mesozoic than in the Permian. From the standpoint of comparative morphology, however, this is unlikely, for these insects are generally recognized as being the most primitive of any insects now existing. The Mesozoic and Tertiary records of the Blattids are also very constant, and since that of the Mesozoic is far ahead of the one in the Tertiary, we certainly cannot look for a reversal of the present ratios. The figures of all the geological periods point definitely to the conclusion that the cockroaches reached their highest development in the number of species during the Upper Carboniferous, and have been decreasing right down to the present time. Of all our records that of the cockroaches is the least open to radical change. The last order on our list, the Orthoptera, has turned up rather regularly in the various geological formations, and the percentage of the Mesozoic species is so far ahead of either 
the Permian or the Tertiary that we are justified in concluding that the order reached its maximum development during the Mesozoic.

For my own part, therefore, I believe that the above percentages, indicating the relative abundance of the species in each order during the several geological periods, is approximately correct for all the orders mentioned, except probably the Neuroptera and Coleoptera. On that basis, at any rate, we may separate the orders into several groups, based upon the time of the maximum development of the order. The Mecoptera, Homoptera, Psocoptera, Plectoptera, and Blattaria are alike in that they had reached their maximum by the Permian. This result is not at all surprising when we reflect that this is precisely what we should expect from the morphology of these insects. For a comparative study of their structure has demonstrated that every one of the orders mentioned is very primitive. It is probable, as I have noted above, that the Neuroptera belong to this series. The next group of orders, those which reached their highest development in the number of species during the Mesozoic, includes the Odonata and the Orthoptera. Here again we find this situation perfectly consistent with the results of comparative morphologists, for these two orders, while primitive in many respects, are a little more highly specialized than those which we have just considered. There remains, then, only a single order, the Diptera, which at present seems to have attained its peak during the Tertiary. And once more we are consistent in our conclusions with those of morphological studies, for the flies are more highly specialized than any of the orders included in the foregoing groups. In this discussion of the development of the insect orders, I have omitted any mention of the Perlaria or stone-flies, because just at present the geological record of these insects is much confused owing to difficulties in interpreting the venation. I have also omitted reference to certain other groups, such as the Heteroptera, Trichoptera, Lepidoptera, Isoptera, and Hymenoptera, none of which has been found in rocks older than the Mesozoic. All these appear to be younger groups, with a shorter and perhaps less completely known geological history than the ones which we have considered. Most of them 
seem to have increased in the number of species right up to the present time.

As I bring to a close this discussion of insect paleontology, I cannot resist a feeling of curiosity as to just what discoveries will take place during the next few years, and just how much our present conception of the geological history of the insects will have to be modified by the end of this next decade. I have already ventured to predict above that certain existing orders will some time be found in Carboniferous rocks, and have demonstrated that we must eventually find winged insects in the Lower Carboniferous and probably also in the Devonian. Just how soon this discovery will be made depends upon the coöperation which the entomologists receive from the geologists. For the student of fossil insects is, on the whole, utterly dependent upon the geologists not only to discover but also to collect his specimens. It is impossible to predict whether or not fossil insects will be found in any one deposit; consequently, their discovery can only be made by someone who is already occupied with the study of that particular formation from some geological aspect. And even when a formation is known to contain insects, these fossils are so scarce that usually it is not practical to work the beds for insects alone. Of course there are a few insect-bearing strata, such as the Wellington Shales of Kansas and the Florissant Shales of Colorado, which contain a sufficiently high percentage of insects so that an expedition of that nature is worth while. But these beds are exceptions. It is upon the geologist who is investigating some other aspect of the strata that we must depend for our fossils. For this reason it is particularly deplorable-and I. make this statement with all due apologies to the few exceptions--that geologists have not favored us in late years with their needed coöperation. While recently visiting one of the larger eastern universities, I was much astonished to find in the possession of the geological department a splendid wing of a Paleodictyopteran, complete from the apex to the base, and showing every vein with gratifying clearness. The specimen was without locality label, and no one appeared to know just where it was collected; for several years the specimen had been used in the elementary geology class as an example of 
a fossil insect, and has passed thru so many inexperienced hands that all its brightness and freshness had gone! Let us therefore hope that the geologist, the paleobotanist, and other paleontologists, will be on the alert for fossil insects, and that once having found them, will place them in the hands of one who can give the fossils the necessary attention. Perhaps this is too much to expect in these days, when the vision of the average geologist is so obscured by petroleum; but by this means alone will we ever locate a Devonian or Mississippian winged insect,- - a find which would contribute more to our knowledge of the origin of the class Insecta than any other single discovery. 

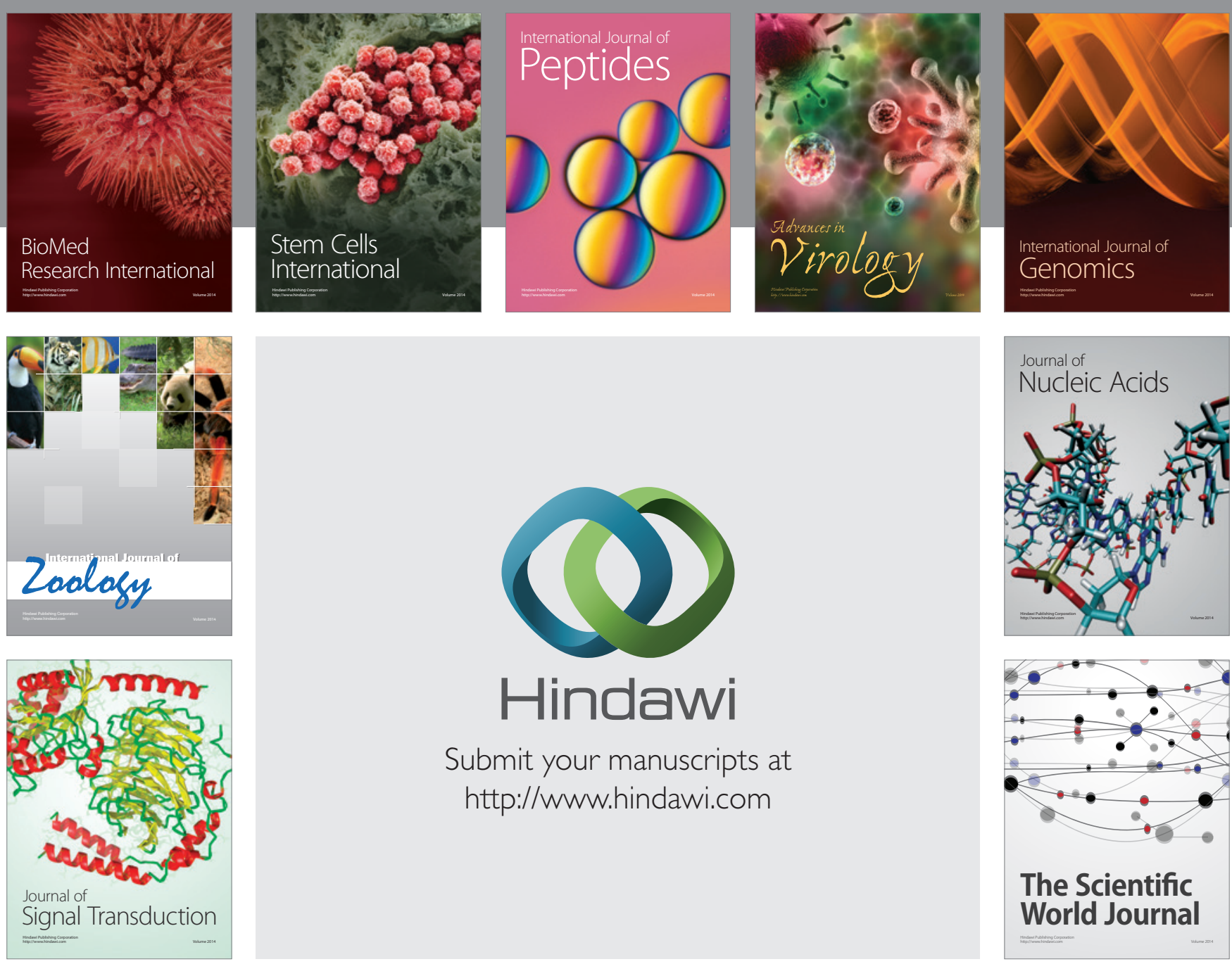

Submit your manuscripts at

http://www.hindawi.com
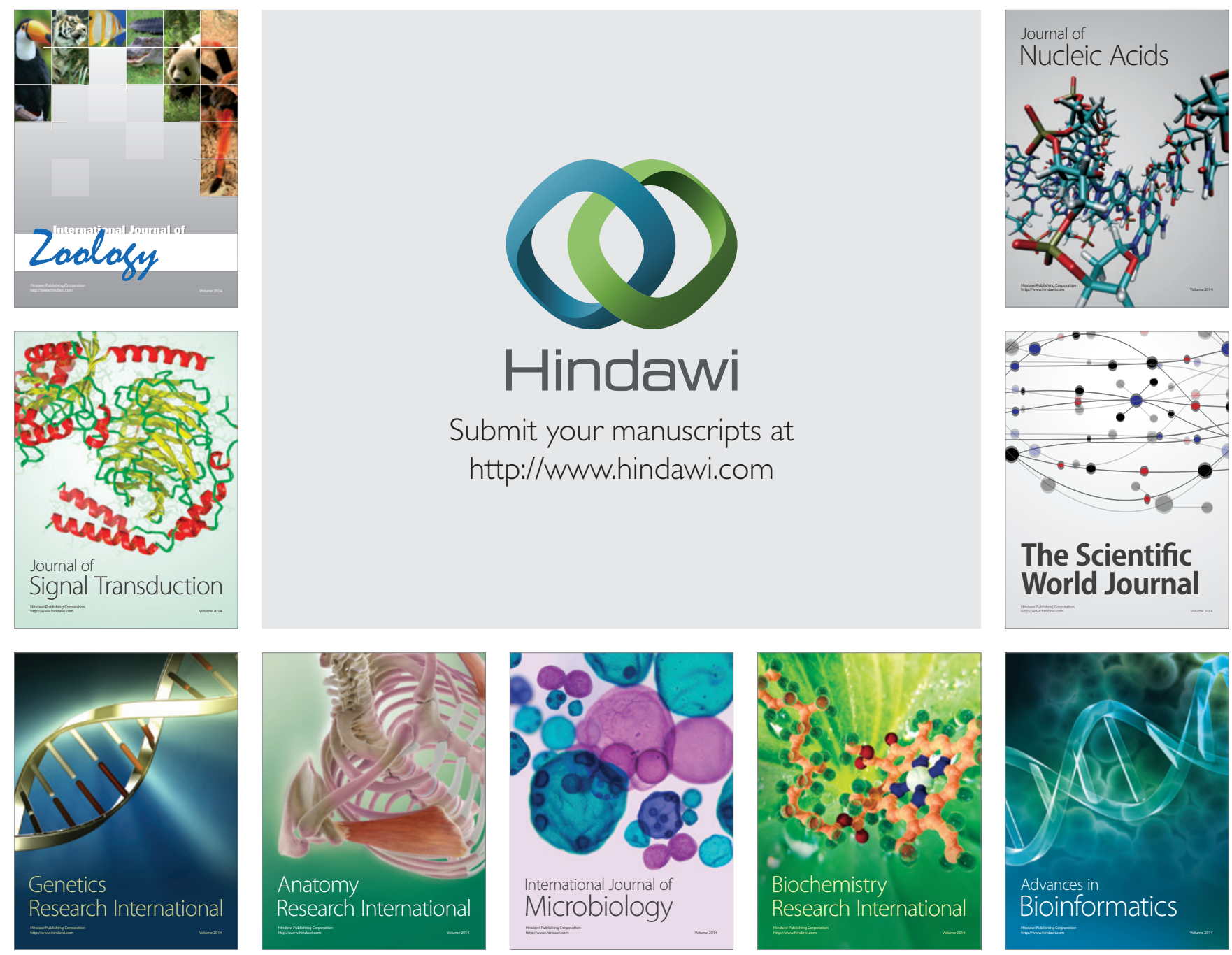

The Scientific World Journal
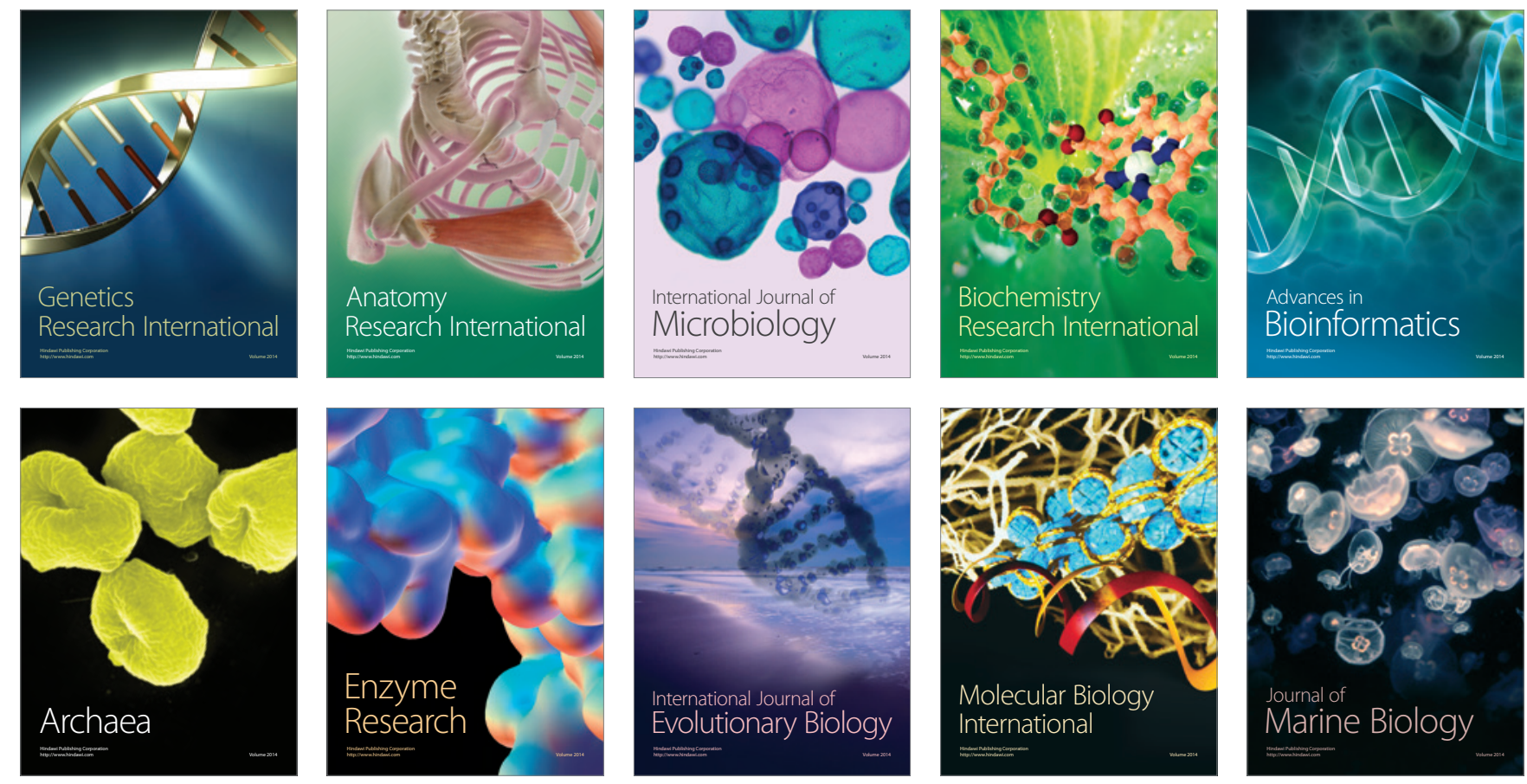